\title{
Application of fuzzy time series forecasting approach for predicting an enterprise net income level
}

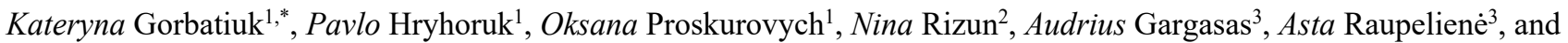 \\ Tea Munjishvili ${ }^{4}$ \\ ${ }^{1}$ Khmelnytskyi National University, Faculty of Economics and Management, Department of Automated Systems and Modeling in \\ Economics, 11 Instytutska Str., Khmelnytskyi, 29016, Ukraine \\ ${ }^{2}$ Gdańsk University of Technology, Faculty of Management and Economics, Department of Informatics in Management, 11/12 Gabriela \\ Narutowicza Str., 80-233 Gdańsk, Poland \\ ${ }^{3}$ Vytautas Magnus University, Faculty of Bioeconomy Development, Business and Rural Development Research Institute, 11 Studentu \\ Str., Akademija, LT-52261 Kaunas, Lithuania \\ ${ }^{4}$ Iv. Javakhishvili Tbilisi State University, Faculty of Economics and Business, Department of Information Technology in Economics and \\ Business, 1 Chavchavadze Ave., 0107 Tbilisi, Georgia
}

\begin{abstract}
To ensure the sustainable development of an enterprise, it is necessary to properly analyze the enterprise development, to ground the plans and management decisions on effective diagnostics and prediction of current and future economic situation at the enterprise. The article presents a study on the application of fuzzy time series forecasting methods. A new approach is applied to forecasting an enterprise's net income using a fuzzy technique. For testing the methodology, there were used statistical data on the enterprise net income level of the Ukrainian enterprise from 2002 to 2017. In the method of Stevenson and Potter, it is proposed to use as the universe of discourse, in the process of applying the method for all defined fuzzy sets, the intervals of variation of such indicator as growth rate. The same background as in Stevenson and Porter's model is used in this article for forecasting the time series levels using the growth rates of the actual data as the universe of discourse. The forecasting results, obtained by this approach, are supposed to have more accuracy rate than other fuzzy time series models. Some modifications of this technique are proposed to obtain a higher accuracy rate and a point forecast one step forward.
\end{abstract}

\section{Introduction}

To strengthen its market position in a competitive environment and guarantee sustainable development, each company must constantly seek reserves to improve its efficiency. The methodology of decision-making processes under the uncertainty in various sectors of the economy are based on the different forecasting methods and models. However, the conditions of uncertainty and variability of the external environment require the use of scientifically sound approaches to management decisions at all stages of production process management, which requires quality planning and forecasting of most important production indicators, as well as systematic adjustment of current and future plans.

As we know, a forecast is any statement about the future, and economic forecasting is a huge subject [1]. Any operational theory of economic forecasting must allow that any characteristic of the data moments (especially measures of averages and spread) might alter because of changes in technology, legislation, politics, weather, and society [1]. The aim of numerous recent researches is to develop effective and reliable methods for economic forecasting. But the most existing forecasting models impose considerable limitations on the random sequences describing the change of economic indicators (Markovian property, stationarity, monotony, scalarity, etc.) [2]. Therefore, the main requirement for forecasting methods, which can be used in decision-making processes, in the absence of any significant restrictions on random sequences that describe changes in economic indicators.

Nowadays, time series forecasts are used in a wide range of economic activities, such as setting monetary and fiscal policies, state and local budgeting, financial management, and financial engineering [2]. At the same time, these forecasting methods use economic theory mainly as a guide to variable selection and rely on past patterns in the data to predict the future [2].

After the publication of Zadeh's fundamental paper on the basics of fuzzy set theory, this theory has become widespread in many areas of research, including economic.

In the latter years, a wide variety of methods have been developed and implemented using fuzzy sets for a description of the uncertainty present in the values of time series. Using fuzzy methods allows to improve the adequacy of description of real-world processes and obtain the sound forecasts of future levels.

\footnotetext{
* Corresponding author: ecvgor@ukr.net
} 
The main objectives of this study are: comparing forecasts based on the obtained models; determining the point estimator for the future net income level obtained by the applied methods for the analysis of this time series of economic indicators; providing recommendations for further use of fuzzy forecasting methods for short-term and operational forecasts of similar economic indicators for economic analysis and modeling of state of the enterprise.

This article consists of six sections. The first section contains the background of the study. The second one provides an overview of the scientific literature on the topic of research. The third part reveals the theoretical details of the proposed fuzzy time series method. The sequence of the study and its main results are presented in the fourth and fifth parts of this work. The final part contains conclusions based on the research results and discussion of further research areas in the field of studying fuzzy time series methods and adapting them to an enterprise economic indicator predicting tasks.

\section{Literature review}

In modern conditions, the importance of forecasting in various spheres of human activity does not require additional substantiation and proof. Forecasting plays a leading role in management decision-making processes. Forecasting gives a certain idea of the future state of various objects and processes, which allows with some confidence level to assess the possible consequences of certain decisions.

Naturally, any forecasting does not give 100\% confidence that the state of objects will be exactly as predicted. That is because any forecasting result contains some uncertainty. Furthermore, the data on which the forecast is based are rarely so deterministic that it is possible to say that there is no uncertainty in them. The uncertainty in the actual data makes it necessary to find new methods of taking it into account.

Fuzzy set theory has been applied to problems of forecasting in different branches of science. The first application of forecasting using fuzzy set theory appeared in Economakos [3]. A simulation-based model was used to forecast the demand for electrical power when load components at various times of the day were described in linguistic terms [4]. Interest in fuzzy forecasting has grown considerably since this initial article [4]. Research on fuzzy forecasting is divided into three categories: qualitative forecasting by the Delphi method, quantitative forecasting by time series analysis, and regression analysis [4]. The second category is the subject of our study.

In particular, the uncertainty of the fuzzy nature is investigated in the so-called fuzzy time series. Many papers on fuzzy time series prediction appeared between 1993 and 2013 (later works mainly developed existing techniques), and many researchers have turned their attention to the fuzzy time series models. Most of the papers published so far have used enrollment data from the University of Alabama as a test sequence over a nearly 20-year period, and proposed models have been compared by the criteria AFER and MSE to choose the best technology by its accuracy rate.

It should be noted that the first work in this direction belonged to Song and Chissom [5]. They introduced the method of creating the time-invariant and the time-variant fuzzy time series models for forecasting the enrollment of the University of Alabama [5]. There were considered the stationary and time-varying fuzzy forecasting models, which provided average forecasting error rates (AFER) of $3.18 \%$ and $4.37 \%$, respectively.

Then, Chen [6] developed three heuristic rules ("informal, intuitive strategies" that express the expectations of expert analysts regarding the trend of student enrollment next year) to calculate the forecasted values by using the midpoints of intervals to derive the forecasted values [7]. Chen's model revised Song and Chissom's time-invariant model in order to simplify the calculations and obtain precise forecasting results. The proposed model used arithmetic operations instead of max-min composition operations found in Song and Chissom's model. As a result, this technique provided an average forecasting error rate of $2.38 \%$.

After that, Huarng [8] improved Chen's model by designing an average-based length method for effectively determining the appropriate interval length. In this direction, $\mathrm{Li}$ and Chen [9] proposed a new interval partitioning approach that applies the rule of natural partitioning (4-3-2) to the enrollment data of the University of Alabama.

The next solution was presented by Jilani et al [10], where the first order and time-variant model was built by the frequency density-based partitioning of the historical enrollment data of the University of Alabama, and applied improved fuzzy metric for forecasting [10]. For this purpose, the universe of discourse was initially divided into equal intervals and a weighted aggregation of the historical enrolments was obtained in each interval [11].

Then, that approach was modified, and a new method was presented by Stevenson and Porter [12], also applying it to modeling enrollment of the University of Alabama using year-to-year percentage change as the universe of discourse (UoD).

Abd Elaal et al [13] proposed model employed eight main steps in time-invariant fizzy and time-variant fuzzy time series for selecting membership functions based on fuzzy clustering [7]. Ismail Z. and Efendi R. [14] presented the weighted fuzzy time series based on a collection of variations of the chronological number in the fuzzy logical group for forecasting trend series data [7].

A summary of most fuzzy forecasting applications in the field of time series forecasting is presented in table 1 $[4,7]$.

In these applications, the fuzzy set theory allows taking into account the uncertainty in the actual data and the different parameters of the models. In general, the structure and application of fuzzy forecasting models are relatively simpler than non-fuzzy models, which makes these models more user-friendly.

Finally, we can confirm that the main goal of all modifications of the original Song and Chissom's model [5] was the reduction of the average forecasting error rate, but some models give the same or not better results than 
the original model. At the same time, a number of techniques have been developed that have significantly improved the accuracy of fuzzy time series models. Some applications of the proposed methods to real problems are presented in [21-27], which confirms the practical value and prospects of these model's application.

Table 1. Fuzzy time series forecasting models in 1989-2011.

\begin{tabular}{|c|c|c|}
\hline Author(s) & $\begin{array}{c}\text { Forecasting } \\
\text { Model }\end{array}$ & Application \\
\hline \begin{tabular}{|c|} 
Shnaider and \\
Kandel (1989) \\
{$[15]$}
\end{tabular} & Time series & $\begin{array}{c}\text { Forecast corporate tax } \\
\text { revenues }\end{array}$ \\
\hline $\begin{array}{l}\text { Song and } \\
\text { Chissom } \\
\text { (1993) [5] }\end{array}$ & $\begin{array}{l}\text { Time-invariant } \\
\text { time series }\end{array}$ & $\begin{array}{l}\text { Forecast University of } \\
\text { Alabama enrollment }\end{array}$ \\
\hline $\begin{array}{l}\text { Song and } \\
\text { Chissom } \\
(1993)[16]\end{array}$ & $\begin{array}{c}\text { Time-invariant } \\
\text { and time-variant } \\
\text { time series } \\
\end{array}$ & $\begin{array}{l}\text { Outline procedure for } \\
\text { conducting forecasts }\end{array}$ \\
\hline $\begin{array}{l}\text { Sullivan and } \\
\text { Woodall } \\
(1994)[17]\end{array}$ & $\begin{array}{l}\text { Markov model } \\
\text { and time series }\end{array}$ & $\begin{array}{l}\text { Forecast University of } \\
\text { Alabama enrollment }\end{array}$ \\
\hline $\begin{array}{l}\text { Song and } \\
\text { Chissom } \\
\text { (1994) [18] }\end{array}$ & $\begin{array}{c}\text { Time-variant time } \\
\text { series }\end{array}$ & $\begin{array}{l}\text { Forecast University of } \\
\text { Alabama enrollment }\end{array}$ \\
\hline $\begin{array}{l}\text { Song et al. } \\
(1995)[19]\end{array}$ & Time series & $\begin{array}{l}\text { Modification of earlier } \\
\text { model }\end{array}$ \\
\hline $\begin{array}{c}\text { Chen (1996) } \\
{[6]}\end{array}$ & Time series & $\begin{array}{l}\text { Forecast University of } \\
\text { Alabama enrollment }\end{array}$ \\
\hline $\begin{array}{c}\text { Huarng (2001) } \\
{[8]} \\
\end{array}$ & Time series & $\begin{array}{c}\text { Forecast University of } \\
\text { Alabama enrollment }\end{array}$ \\
\hline $\begin{array}{l}\text { Li S.T., Chen } \\
\text { Y.P. (2004) [9] }\end{array}$ & Time series & $\begin{array}{c}\text { Forecast University of } \\
\text { Alabama enrollment }\end{array}$ \\
\hline $\begin{array}{l}\text { Melike and } \\
\text { Konstantin } \\
(2005)[20]\end{array}$ & $\begin{array}{c}\text { First order fuzzy } \\
\text { time-invariant } \\
\text { time series }\end{array}$ & $\begin{array}{c}\text { Forecast University of } \\
\text { Alabama enrollment }\end{array}$ \\
\hline $\begin{array}{l}\text { Jilani et al } \\
(2007)[10]\end{array}$ & $\begin{array}{c}\text { First-order and } \\
\text { time-variant time } \\
\text { series }\end{array}$ & $\begin{array}{l}\text { Forecast University of } \\
\text { Alabama enrollment }\end{array}$ \\
\hline \begin{tabular}{|c|} 
Stevenson and \\
Porter (2009) \\
{$[12]$} \\
\end{tabular} & $\begin{array}{c}\begin{array}{c}\text { First-order and } \\
\text { time-variant time } \\
\text { series }\end{array} \\
\end{array}$ & $\begin{array}{l}\text { Forecast University of } \\
\text { Alabama enrollment }\end{array}$ \\
\hline $\begin{array}{c}\text { Abd Elaal et al } \\
(2010) \text { [13] }\end{array}$ & $\begin{array}{c}\text { Time-invariant } \\
\text { and time-variant } \\
\text { time series }\end{array}$ & $\begin{array}{c}\text { Forecast University of } \\
\text { Alabama enrollment and } \\
\text { the world production of } \\
\text { iron and steel }\end{array}$ \\
\hline $\begin{array}{l}\text { Ismail Z. and } \\
\text { Efendi R. } \\
\text { (2011) [14] }\end{array}$ & $\begin{array}{l}\text { Weight fuzzy } \\
\text { time series }\end{array}$ & $\begin{array}{c}\text { Forecast for University of } \\
\text { Alabama and the } \\
\text { University of Technology } \\
\text { Malaysia }\end{array}$ \\
\hline
\end{tabular}

\section{Research methodology}

In our research, we used Stevenson and Porter's model with some modifications made to improve the accuracy rate and obtain the forecast point estimate one step forward. We used the same background as in Stevenson and Porter's model for forecasting time series using percentage change of the actual data as the universe of discourse (UoD).

In the method of Stevenson and Potter, it is proposed to use as the universe of discourse [12], on which fuzzy sets are given, the intervals of variation of such indicators as the percentage change of year to year rates [12], which we will hereinafter call "chain growth rates" or "growth rates".

Consider the time series of a certain economic indicator, which levels are denoted by $y_{i}, i=\overline{1, n}$.

To model time series, the proposed method uses the following dynamics indicator as a chain growth rate:

$$
T_{i}=\left(\frac{y_{i}}{y_{i-1}}-1\right) \times 100 \%, i=\overline{2, n} .
$$

The algorithm of proposed by Stevenson and Porter method contains the following steps [12]:

Step 1. Determine the universe of discourse as the set $U=\left[\min _{i=2, n} T_{i} ; \max _{i=2, n} T_{i}\right]$, and divide it into m equal intervals (in the Stevenson and Porter's model $m=7$ ). It is desirable to round the boundaries of this set to the nearest integer values. But, in our case, for better accuracy, we left the calculated values without correction.

Step 2. Find the frequency distribution of the values of the growth rates that fall into each interval of the partition. By the rule of natural partitioning (4-3-2), for the three largest values of frequencies that fall into certain intervals, make an additional dividing of these intervals into smaller 4, 3, and 2 sub-intervals, respectively. The number of intervals $\mathrm{m}$ recalculates here, and it takes a new value.

Step 3. Define fuzzy sets $X_{j}, j=\overline{1, m}$ on each partition interval as triangular fuzzy numbers, which carriers are described by three values: lower limit, middle point, and upper limit. For the actual data of the time series, determine which fuzzy set will describe each value, thereby fuzzifying the data of the initial series.

Step 4. Perform the defuzzification of fuzzy data using the formula:

$$
t_{j}=\left\{\begin{array}{l}
\frac{1+0.5}{\frac{1}{a_{1}}+\frac{0.5}{a_{2}}}, j=1 \\
\frac{0.5+1+0.5}{0.5}+\frac{1}{a_{j-1}}+\frac{0.5}{a_{j+1}}, 2 \leq j \leq m-1 \\
\frac{0.5+1}{\frac{0.5}{a_{j-1}}+\frac{1}{a_{j}}}, j=m
\end{array}\right.
$$

where $a_{j-1}, a_{j}, a_{j+1}$ are the middle points of the intervals of the carriers of fuzzy sets $X_{j-1}, X_{j}, X_{j+1}$, respectively.

Step 5. Determine the predicted values of each level of the series, using the obtained $t_{i}$ and consistently applying them to previous levels by the formula:

$$
\hat{y}_{i}=y_{i-1}\left(1+\frac{t_{i}}{100}\right), i=\overline{2, n} .
$$

As shown on the data of the University of Alabama enrollment [12], the forecasting results, obtained by this approach, are supposed to have more accuracy rate than other fuzzy time series models. 


\section{Case study: Net income forecasting using fuzzy time series}

Consider such an indicator of the enterprise production activity LLC (Limited Liability Company) "Ukrelektroaparat" (Khmelnytskyi) as net income (revenue) from sales. Data on the net income (revenue) from sales in cash equivalent for the period from 2002 to 2018 were obtained from the reporting documentation of the enterprise LLC "Ukrelektroaparat" from open sources of information and presented graphically in Figure 1.

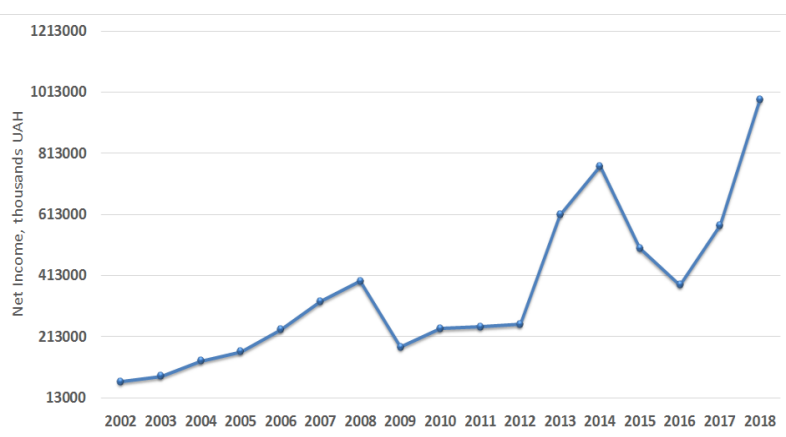

Fig. 1. Dynamics of the net income in 2002-2018.

So, we considered this time series of a real economic indicator and applied to it the fuzzy time series forecasting method described above. Firstly, the growth rates were calculated and aggregated in Table 2.

Table 2. Actual values and the growth rates of net income.

\begin{tabular}{|c|c|c|}
\hline Year to Year & $\boldsymbol{y}_{\boldsymbol{i}}$ & Growth rate, $\boldsymbol{T}_{\boldsymbol{i}}$ \\
\hline $2002-2003$ & 82576 & 28.02 \\
\hline $2003-2004$ & 132605 & 60.59 \\
\hline $2004-2005$ & 163642 & 23.41 \\
\hline $2005-2006$ & 235708 & 44.04 \\
\hline $2006-2007$ & 327632 & 39.00 \\
\hline $2007-2008$ & 393463 & 20.09 \\
\hline $2008-2009$ & 178079 & -54.74 \\
\hline $2009-2010$ & 239518 & 34.50 \\
\hline $2010-2011$ & 244659 & 2.15 \\
\hline $2011-2012$ & 253295 & 3.53 \\
\hline $2012-2013$ & 610840 & 141.16 \\
\hline $2013-2014$ & 769940 & 26.05 \\
\hline $2014-2015$ & 501278 & -34.89 \\
\hline $2015-2016$ & 382031 & -23.79 \\
\hline $2016-2017$ & 576795 & 50.98 \\
\hline $2017-2018$ & 986778 & 71.08 \\
\hline
\end{tabular}

Given the actual interval of variation of the growth rates from $-54.74 \%$ to $141.16 \%$, it is proposed to determine the universe of discourse as the set $\mathrm{U}=[-54.74 ; 141.16]$, and divide it into the seven intervals. The frequencies of growth rates in occurred in each interval are calculated and presented in Table 3.

Then, we applied the rule (4-3-2) of natural partitioning. As we can see, the largest numbers of net income growth rates have fallen in the fourth, fifth, and sixth intervals, which we divided then into 4, 3, and 2 equal subintervals, respectively. Finally, we obtained the fuzzy sets with triangular membership functions as described in Figure 2.
Table 3. Actual values and the growth rates of net income.

\begin{tabular}{|c|c|c|c|}
\hline $\begin{array}{c}\text { Interval } \\
\text { number }\end{array}$ & Lower limit & Upper limit & Frequency \\
\hline 1 & -54.74 & -26.76 & 1 \\
\hline 2 & -26.76 & 1.23 & 1 \\
\hline 3 & 1.23 & 29.22 & 1 \\
\hline 4 & 29.22 & 57.20 & 6 \\
\hline 5 & 57.20 & 85.19 & 4 \\
\hline 6 & 85.19 & 113.17 & 2 \\
\hline 7 & 113.17 & 141.16 & 0 \\
\hline
\end{tabular}

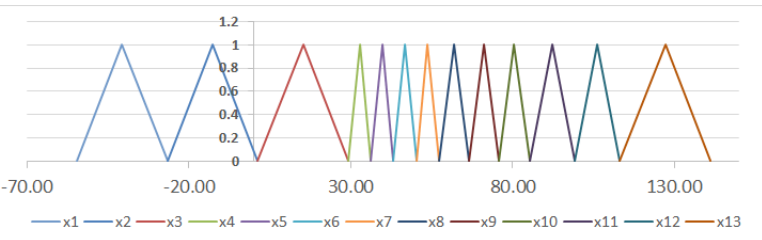

Fig. 2. Fuzzy sets with triangular membership functions.

The final partition of the universe of discourse, the description of the fuzzy sets' carriers with corresponding triangular membership functions and the defuzzified values, are given in Table 4.

Using the obtained defuzzified indicators $t_{i}$ we determined the predicted values for each time series level, consistently applying them to the previous levels by the formula (3).

The results of calculations of the predicted levels for the considered time series are summarized in table 5. Also, there are represented the determined average forecasting error rates (AFER) obtained by the proposed method by the formula:

$$
A F E R=\frac{\left|y_{i}-\hat{y}_{i}\right| / y_{i}}{n} \times 100 \% .
$$

Table 4. Fuzzy sets and their parameters.

\begin{tabular}{|c|c|c|c|c|}
\hline \multirow{2}{*}{$\begin{array}{c}\text { Fuzzy } \\
\text { set }\end{array}$} & \multicolumn{3}{|c|}{ Carrier of fuzzy set } & \multirow{2}{*}{$\begin{array}{c}\text { Defuzzified } \\
\text { value, } \boldsymbol{t}_{\boldsymbol{j}}\end{array}$} \\
\cline { 2 - 4 } & $\begin{array}{c}\text { Lower } \\
\text { limit }\end{array}$ & $\begin{array}{c}\text { Middle } \\
\text { point, } \boldsymbol{a}_{\boldsymbol{j}}\end{array}$ & $\begin{array}{c}\text { Upper } \\
\text { limit }\end{array}$ & \\
\hline$X_{1}$ & -54.74 & -40.75 & -26.76 & -23.54 \\
\hline$X_{2}$ & -26.76 & -12.76 & 1.23 & -34.61 \\
\hline$X_{3}$ & 1.23 & 15.22 & 29.22 & 47.85 \\
\hline$X_{4}$ & 29.22 & 32.71 & 36.21 & 26.31 \\
\hline$X_{5}$ & 36.21 & 39.71 & 43.21 & 39.08 \\
\hline$X_{6}$ & 43.21 & 46.71 & 50.20 & 46.18 \\
\hline$X_{7}$ & 50.20 & 53.70 & 57.20 & 53.46 \\
\hline$X_{8}$ & 57.20 & 61.87 & 66.53 & 61.54 \\
\hline$X_{9}$ & 66.53 & 71.19 & 75.86 & 70.58 \\
\hline$X_{10}$ & 75.86 & 80.52 & 85.19 & 80.43 \\
\hline$X_{11}$ & 85.19 & 92.18 & 99.18 & 91.88 \\
\hline$X_{12}$ & 99.18 & 106.18 & 113.17 & 106.53 \\
\hline$X_{13}$ & 113.17 & 127.16 & 141.16 & 119.30 \\
\hline
\end{tabular}

The values of the initial time series and the obtained forecasted levels are represented in Figure 3, and they also can be compared with the values of the simple moving average (Figure 4), which shows that deviations of fuzzy 
forecasting results from initial values are much lower than of the moving average.

Table 5. Forecasting results for the net income.

\begin{tabular}{|c|c|c|c|c|c|c|}
\hline $\boldsymbol{i}$ & $\boldsymbol{y}_{\boldsymbol{i}}$ & $\boldsymbol{T}_{\boldsymbol{i}}$ & $\boldsymbol{X}_{\boldsymbol{j}}$ & $\boldsymbol{t}_{\boldsymbol{j}}$ & $\widehat{\boldsymbol{y}}_{\boldsymbol{i}}$ & $\boldsymbol{A F E R}$ \\
\hline 1 & 64500 & - & - & - & - & - \\
\hline 2 & 82576 & 28.02 & $X_{3}$ & 47.85 & 95364 & 0.1549 \\
\hline 3 & 132605 & 60.59 & $X_{8}$ & 61.54 & 133396 & 0.0060 \\
\hline 4 & 163642 & 23.41 & $X_{3}$ & 47.85 & 196058 & 0.1981 \\
\hline 5 & 235708 & 44.04 & $X_{6}$ & 46.18 & 239206 & 0.0148 \\
\hline 6 & 327632 & 39.00 & $X_{5}$ & 39.08 & 327833 & 0.0006 \\
\hline 7 & 393463 & 20.09 & $X_{3}$ & 47.85 & 484407 & 0.2311 \\
\hline 8 & 178079 & -54.74 & $X_{1}$ & -23.54 & 300838 & 0.6894 \\
\hline 9 & 239518 & 34.50 & $X_{4}$ & 26.31 & 224939 & 0.0609 \\
\hline 10 & 244659 & 2.15 & $X_{3}$ & 47.85 & 354130 & 0.4474 \\
\hline 11 & 253295 & 3.53 & $X_{3}$ & 47.85 & 361731 & 0.4281 \\
\hline 12 & 610840 & 141.16 & $X_{13}$ & 119.30 & 555485 & 0.0906 \\
\hline 13 & 769940 & 26.05 & $X_{3}$ & 47.85 & 903133 & 0.1730 \\
\hline 14 & 501278 & -34.89 & $X_{1}$ & -23.54 & 588689 & 0.1744 \\
\hline 15 & 382031 & -23.79 & $X_{2}$ & -34.61 & 327767 & 0.1420 \\
\hline 16 & 576795 & 50.98 & $X_{7}$ & 53.46 & 586281 & 0.0164 \\
\hline 17 & 986778 & 71.08 & $X_{9}$ & 70.58 & 983882 & 0.0029 \\
\hline \multicolumn{2}{|c|}{ Total } & - & - & - & - & 2.831 \\
\hline AFER & - & - & - & - & $17.7 \%$ \\
\hline \multicolumn{7}{|c|}{}
\end{tabular}

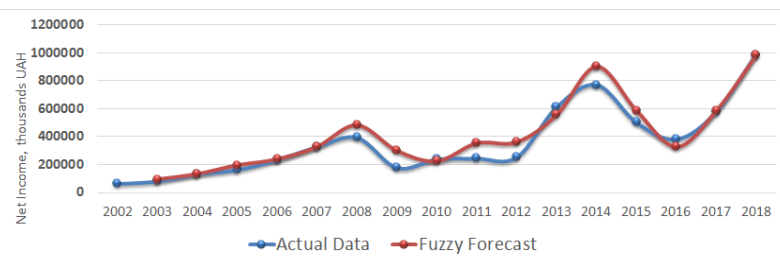

Fig. 3. Comparison of the modeling results with the actual data.

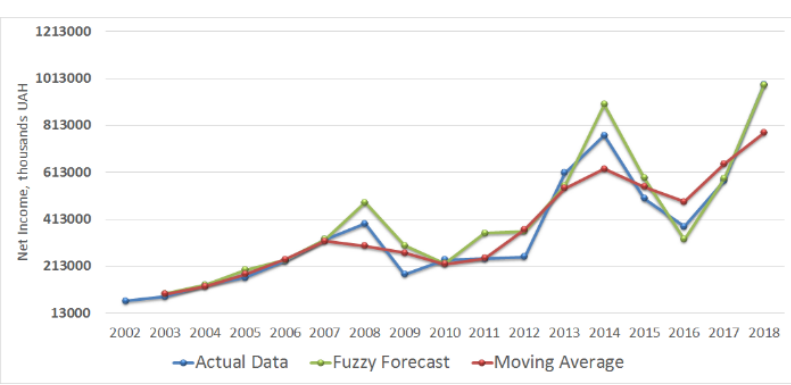

Fig. 4. Forecasted levels compared with the simple moving average.

Another way to test this methodology is to take the time series values from 2002 to 2017 as the initial values and to build the fuzzy time series model on them. Using the fuzzy sets describing the predictive level of each time series level, we can consider a defuzzified value of the time series as a point forecast estimate for each level. Therefore, we suggest calculating the forecasted value for 2018 using the last fuzzy set definition $X_{7}$ (for the year 2017), and to obtain the predicted value by the formula:

$$
\hat{y}_{17}=y_{16}\left(1+\frac{t_{7}}{100}\right) \text {. }
$$

The result of estimation is $\hat{y}_{17}=899733$ thousand UAH (Figure 5), and the average forecasting error rate for this model is AFER $=9.8 \%$, which is slightly lower than for the previous model (table 4). The actual value for 2018 is 986778 thousand $\mathrm{UAH}$, so the relative error is $8.8 \%$.

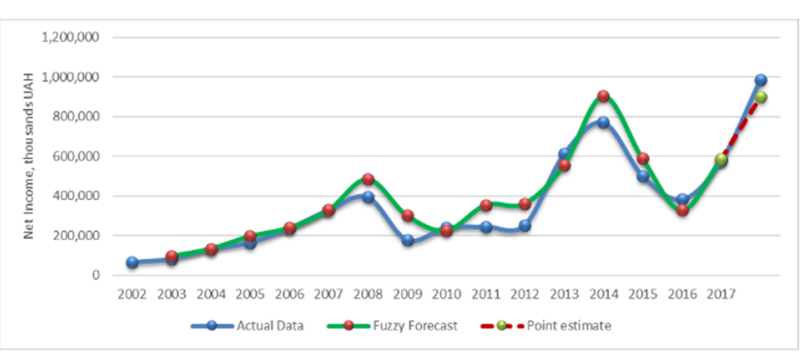

Fig. 5. Point forecast estimate of the net income for 2018.

The accuracy of this forecasting model could be improved if we try to minimize the average forecasting error rate by adjusting some of the values in the defuzzification formula (2). We suggest using four parameters $\alpha_{1}, \alpha_{2}, \beta_{1}, \beta_{2}$ instead of the values 0.5 in (2):

$$
t_{j}^{a d j}=\left\{\begin{array}{l}
\frac{1+\alpha_{1}}{\frac{1}{a_{1}}+\frac{\alpha_{1}}{a_{2}}}, j=1 ; \\
\frac{\beta_{1}+1+\beta_{2}}{\frac{\beta_{1}}{a_{j-1}}+\frac{1}{a_{j}}+\frac{\beta_{2}}{a_{j+1}}}, 2 \leq j \leq n-1 ; \\
\frac{\alpha_{2}+1}{\frac{\alpha_{2}}{a_{j-1}}+\frac{1}{a_{j}}}, j=n .
\end{array}\right.
$$

These parameters could be optimized using the Excel Solver GRG Nonlinear method, where AFER is to be set as the objective function, which needs to be minimized. In our study, one set of the obtained adjusted values is: $\alpha_{1}=-0.104, \quad \alpha_{2}=-0.334, \quad \beta_{1}=0.076, \beta_{2}=0.325$. These values are not unique for each case, but we tried to achieve better accuracy for our model. For the obtained adjusted values, the average forecasting error rate is equal to $5.5 \%$, which is much less than this accuracy indicator for the previous model. These results are illustrated in figure 6 , where we can see the forecasted values obtained by the formula (6) with the adjusted parameters.

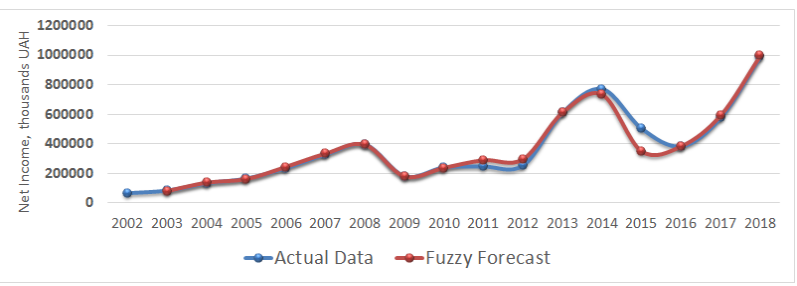

Fig. 6. Net income forecasting model with adjusted parameters.

Comparing to the previous results in Figure 3, this chart shows the closer points to the actual time series levels, which demonstrates the better accuracy of the last obtained model. 


\section{Results and discussion}

As we can see, Stevenson and Porter's method can be applied to the time series of the enterprise's net income level and gives a relatively small error of the result. The conducted analysis shows that the proposed algorithm is quite simple, which makes further searches for the effective methods for modeling time series using fuzzy approach promising, and we should look for the most accurate and convenient fuzzy estimation procedures for time series of economic indicators which take into account the uncertainty of the original data.

Besides, the proposed modification of this technique allows to obtain a point forecast estimate one step ahead, which will give us a piece of information about the possible future level of the time series considered in the research and could be useful for short-term and operational forecasts of similar economic indicators for economic analysis and modeling of state of the enterprise.

\section{Conclusion}

The presented in the article method of fuzzy time series modeling allows obtaining the forecasting estimates by analyzing the growth rates of the actual time series levels using fuzzy estimation based on the fuzzy sets. This approach makes it possible to use all available information on the dynamics of any economic indicator presented with time series, and achieve a relatively low value of the average error rate.

Further research in this direction should be aimed at developing a unified general formula for defuzzification purposes, which will include a set of parameters, which optimization will allow to obtain better accuracy of the predicted values compared to the actual ones. Another priority for further study is to find possible ways to obtain forecasts a few steps ahead, as there is currently a lack of works in this field. Moreover, a lot of published studies have shown that the accuracy of forecasting is directly affected by the method of the partitioning of the universe of discourse into the set of fuzzy subsets. So, the recommendations should also be developed for the optimal distribution of values over split intervals. Therefore, the use of fuzzy time series approaches opens wide prospects in the field of simplifying the analysis and modeling of time series of economic indicators. Improving such methods will provide an opportunity to implement better forecasting procedures in decisionmaking systems on enterprises.

\section{References}

1. D.F. Hendry, M.P. Clements, Economic forecasting: some lessons from recent research. Economic Modelling 20(2), 301-329 (2001)

2. J.H. Stock, Time series: economic forecasting, in International Encyclopedia of the Social \& Behavioral Sciences (2001), pp. 15721-15724
3. E. Economakos, Application of fuzzy concepts to power demand forecasting. IEEE Trans. Syst. Man Cybern. 9, 651-657 (1979)

4. A.L. Guiffrida, R. Nagi, Fuzzy set theory applications, in production management research: a literature survey. J. Intell. Manuf. 9, 39-56 (1998)

5. Q. Song, B.S. Chissom, Fuzzy time series and its models. Fuzzy Sets and Syst. 54, 269-277 (1993)

6. S.M. Chen, Forecasting enrollments based on fuzzy time series,. Fuzzy Sets and Syst. 81, 311-319 (1996).

7. Y. Shakmak, S.M. Boaisha, S. Awami, An optimal general trend for fuzzy time series forecasting based on intervals fuzzy rules based high-order partitioning mathematics (2011)

8. K. Huarng, Effective lengths of intervals to improve forecasting in fuzzy time series. Fuzzy Sets and Syst. 12, 387-394 (2001)

9. S.T. Li, Y.P.Chen, Natural partitioning based forecasting model for fuzzy time series, in Proc. of the IEEE International Conference on Fuzzy Systems, vol. 3 (Budapest, Hungary, 2004), p. 1355

10. T.A. Jilani, S.M. Burney, A. Ardil, Fuzzy metric approach for fuzzy time series forecasting based on frequency density based partitioning, in Proc. of World Academy of Science, Engineering and Technology, vol. 34 (2007)

11. A.S. Olaniyi, O.A. Okunade, A fuzzy time-series approach to enrolment forecasting. Afr J. of Comp \& ICT 4, 41-46 (2011)

12. M. Stevenson, J.E. Porter, Fuzzy time series forecasting using percentage change as the universe of discourse, in Proc. of World Academy of Science, Engineering and Technology, vol. 55, (2009), p. 153

13. A.K. Abd-Elaal, H.A. Hefny, A.H. Abd-Elwahab, An improved fuzzy time series model for forecasting. IJCSIS 8, 140-147 (2010)

14. Z. Ismail, R. Efendi, Enrollment forecasting based on modified weight fuzzy time series. J. Artif. Intell. 4, 110-118 (2011)

15. E. Shnaider, A. Kandel, The use of fuzzy set theory for forecasting corporate tax revenues. Fuzzy Sets and Syst. 31, 187-204 (1989)

16. Q. Song, B.S. Chissom, Forecasting enrollments with fuzzy time series: Part I. Fuzzy Sets and Syst. 54, 19 (1993)

17. J. Sullivan, W.H. Woodall, A comparison of fuzzy forecasting and Markov modeling. Fuzzy Sets and Syst. 64, 279-293 (1994)

18. Q. Song, B.S. Chissom, Forecasting enrollments with fuzzy time series: Part II. Fuzzy Sets and Syst. 62, 18 (1994)

19. Q. Song, R.P. Leland, B.S. Chissom, A new fuzzy time-series model of fuzzy number observations. Fuzzy Sets and Syst. 73, 341-348 (1995)

20. S. Melike, Y.D. Konstantin, Forecasting enrollment Model based on first-order fuzzy time series, in Proceedings of World Academy of Science, 
Engineering and Technology, vol. 1, (January, 2005), p. 375

21. S. Xihao, L. Yimin, Average-based fuzzy time series models for forecasting Shanghai compound index. WJMS 4, 104-111 (2008)

22. J.H. Pujar, Fuzzy ideology based long term load forecasting. IJCTE 4 (4), 790-795 (2010)

23. S.M. Boaisha, S.M. Amaitik, Forecasting model based on fuzzy time series approach, in Proc. of the 10th International Arab Conference on Information Technology (2010)

24. N. Kumar, S. Ahuja, V. Kumar, A. Kumar, Fuzzy time series forecasting of wheat production. IJCSE 2, 635-640 (2010)

25. S. Ahmadi, H. Bevrani, H. Jannaty, A fuzzy inference model for short-term load forecasting, in Proc. of the Second Iranian Conference on Renewable Energy and Distributed Generation (2012), p. 39

26. S. Rajaram, V. Vamitha, A modified approach on fuzzy time series forecasting. APAM 2, 96-106 (2012)

27. C.H. Su, C.H. Cheng, W.L. Tsai, Fuzzy time series model based on fitting function for forecasting TAIEX index. Int. J. Hybrid Inf. Technol. 6, 111-122 (2013) 